\title{
FURTHER OBSERVATIONS ON THE FINE STRUCTURE OF CHRYSOCHROMULINA ERICINA PARKE \& MANTON
}

\author{
By I. MANTon and G. F. LeEDALE ${ }^{1}$ \\ Botany Department, Leeds University \\ (With 29 Figures on Plates I-VII)
}

The observations to be presented supplement the previous taxonomic description of the species (Parke, Manton \& Clarke, I956) in several respects. Chrysochromulina ericina is one of six marine species attributed to Chrysochromulina by Parke, Manton \& Clarke in 1955 and 1956 , and described with the aid of low resolution electron microscopy of external morphology only. Subsequent observations on two further species of Chrysochromulina (Parke, Manton \& Clarke, 1958, 1959), which included some information on microanatomy from higher resolution electron microscopy of thin sections, had revealed structural differences between them which could not be taxonomically assessed without a broader basis of comparison. Since the easiest way of supplying this is to re-investigate with newer methods some of the existing named species, $C$. ericina was selected for this purpose as an obvious first choice.

The structural differences found in the two anatomically investigated species (C. chiton and C. strobilus) include the number of fibres in the core of the haptonema ( 7 in C. chiton and 6 in C. strobilus), the form and position of the pyrenoid (immersed in C. strobilus, but an external diverticulum on the chromatophore in $C$. chiton) and the very peculiar character of the Golgi structure in C. strobilus, of a kind which is either undemonstrated or absent in $C$. chiton. The new anatomical observations have been directed to ascertaining the facts on these particular matters for the species under investigation, but in addition $C$. ericina possesses a type of superficial scale (long tapering spines with flared base) which has not been encountered so far in other species but which cannot be completely described without the aid of sections. The difficulty of interpreting the morphology of the scales without this information is therefore the special reason for selecting this species for further study.

1 Development Commission Fellow seconded by the Marine Biological Association to Leeds University for the academic year $1959-60$ to work on this and other problems. 


\section{MATERIAL AND METHODS}

The material is exactly the same as before, consisting of cultures representing the holotype of $C$. ericina supplied from Plymouth as required. The electron microscopical methods are exactly as in Parke et al. (1958, 1959), but advantage has been taken of an opportunity to apply additional light optical methods and only these need be explained in detail.

In 1956 photographic observations with the light microscope had been limited to dried cells, in which the spines could be seen, though with difficulty, and to a few examples of cells fixed in iodine and photographed under oil immersion to demonstrate ingestion of carbon pellets supplied to the culture in the form of Aquadag for the purpose of investigating phagotrophic feeding.

By the use of dark ground illumination it has now been possible to photograph various conditions of the haptonema in iodine-fixed material and by the use of anoptral contrast to photograph the organism alive.

The photographs of living cells reproduced (Pls. I and II) have been made with a Reichert Zetopan microscope fitted with a $\mathrm{r} \cdot 8 \mathrm{~mm}$ anoptral contrast, achromatic, oil-immersion objective ( $\times$ I00) N.A. I $\cdot 25$, used with an aplanatic $\times$ Io eyepiece and a Polyphos condenser. With a $30 \mathrm{~W}$ light source and no filters the possible exposure times on Ilford H.P.S. plates are $\frac{1}{5}$ and $\frac{1}{2}$ sec. This is sufficiently short for all but rapidly swimming cells. Slight flattening of living cells by coverslip pressure, easily obtained by gradual evaporation of water from an unsealed mount, facilitates examination of cell contents and it is often instructive to allow cells to flatten until they burst.

\section{NEW OBSERVATIONS WITH THE LIGHT MICROSCOPE}

One of the first new observations which could easily be made with anoptral contrast was to trace the differences in incidence of spined scales from cell to cell. Substantial differences occur. Figs. 6 and 7 are two successive conditions of a cell which is being squeezed to death by pressure from the coverslip, and it is at once obvious that the scales are conspicuous objects which can be counted exactly under this treatment. The numbers actually encountered varied from o to 24. In cultures sent by rail from Plymouth a majority of cells without spines is always present, doubtless in part as a direct consequence of the disturbances involved in the journey. On subculturing the average number of spines per cell builds up rapidly for the first couple of weeks, after which it falls again until in old cultures (I-3 months) cells with many spines may be difficult to find though they can always be recovered in small numbers from the coolest part of the culture near the bottom of the flask. Some actual figures obtained from counts on two different ages of culture are recorded in Table I. 
For study of the internal organs in intact living cells, the absence of scales is an advantage and the cells shown in Figs. $\mathrm{I}-4$ are in this condition. The bifid chromatophores are conspicuous, see especially Figs. I and 3. When a cell has actually burst by flattening (Fig. 4) the chromatophores swell and become circular in face view before eventually disintegrating. For a short time before this happens striations radiating from an unstriated central area are conspicuous (Fig. 4); the latter almost certainly corresponds to the pyrenoid which in other views, notably Fig. 5, may appear dense (i.e. bright).

\section{TABLE 1. COMPARISON OF SPINE NUMBERS IN AN OLD CULTURE}

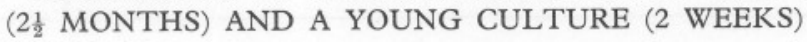

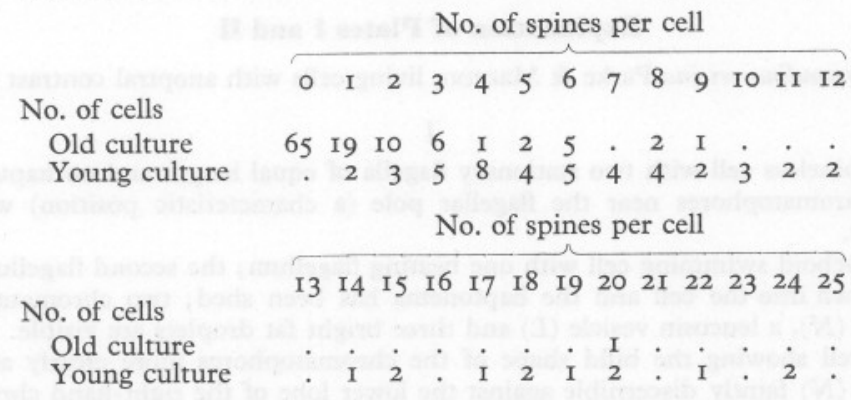

The nucleus is always inconspicuous and is very frequently masked by one lobe of a chromatophore; it is, nevertheless, distinct in Fig. $2(N)$ and faintly visible in Fig. $3(N)$, in both cases the spherical nucleolus and the curve of the nuclear membrane being the only ascertainable features.

The cell membrane is best seen in Fig. 5 in which, under pressure, the underlying cytoplasm has separated from it in several places. Two undischarged muciferous bodies have maintained contact with the inner side of the cell membrane on the left, where they can be seen as small bright spheroids. Examples of discharged muciferous bodies are included in Fig. IO (arrows) where they take the form of delicate strands sometimes ending in a spheroid and often of very considerable length.

The only other internal organs which can be identified with certainty are some spherical oil droplets (very bright in all these cells) and a large sphere of alcohol-soluble material which we believe to be leucosin ( $L$ in Figs. 2-4) sometimes with a central inclusion of unknown nature. Other vesicles of various sizes and with or without contents can be seen from time to time (e.g. Figs. 3 and 4 ) though without certainty as to their nature. Additional cell organelles known to be present on other evidence, notably mitochondria and Golgi bodies, are not demonstrable by these methods and there is therefore nothing to add to the previous account (Parke et al. 1956, p. 395).

The various manifestations of cell movement recorded from unflattened living cells assembled in Plate II compare closely with drawings previously 
published and need little further explanation. Attention should, however, be directed to the pseudopodia-like bodies on the cell surface in Fig. 2. They may perhaps be the same as protuberances described as flowing out in relation to phagotrophic feeding (p. 397 of the previous paper), though as seen here they are relatively static structures on a small proportion only of the motile cells. They have not been seen in any special relation to ingestion or egestion and with transmitted light they are so transparent as to be virtually invisible. They are therefore perhaps a previously undescribed type of temporary surface feature.

\section{Explanation of Plates I and II}

Chrysochromulina ericina Parke \& Manton, living cells with anoptral contrast $(\times 2000)$

\section{I}

Fig. I. A spineless cell with two stationary flagella of equal length and no haptonema; two bifid chromatophores near the flagellar pole (a characteristic position) with a third laterally.

Fig. 2. Amoeboid swimming cell with one beating flagellum; the second flagellum has been withdrawn into the cell and the haptonema has been shed; two chromatophores, the nucleus $(N)$, a leucosin vesicle $(L)$ and three bright fat droplets are visible.

Fig. 3. A cell showing the bifid shape of the chromatophores more clearly and with the nucleus $(N)$ faintly discernible against the lower lobe of the right-hand chromatophore in the centre of the cell; other identifiable cell inclusions are two bright oil droplets of different size and a leucosin vesicle $(L)$; a few spined scales visible in the background (left).

Fig. 4. Remains of a cell immediately after bursting; the leucosin vesicle $(L)$ and fat droplets still intact, the four chromatophores undergoing post-mortem changes which include the appearance of peripheral striations round a central clear area marking the position of the pyrenoid.

Fig. 5. Cell under slight pressure showing the body membrane raised up from the cytoplasm; two undischarged muciferous bodies are still attached to the inner side of the body membrane (left); chromatophores near the flagellar pole viewed from the side show the pyrenoids $(P y)$ as bright inclusions; fat droplets and other cell inclusions visible; detached scales in the background.

Figs. 6, 7. Two successive stages of a cell under pressure until it bursts (Fig. 7). In both, a considerable array of scales detached from the surface are visible in the field.

II

Swimming cells $(\times 2000)$

Figs. 8, 9. Two cells with extended haptonema $(H)$ and beating flagella; in Fig. 8 the flagellar beat is relatively slow and in Fig. 9 faster.

Fig. Io. Cell with the two flagella beating slightly and the haptonema $(H)$ partly uncoiled; three thread-like discharges from muciferous bodies are present in the field (arrows).

Fig. II. Stationary cell, with haptonema $(H)$ extended at the base but tightly coiled at the tip.

Fig. I2. Stationary cell with flagella beating slightly and the haptonema $(H)$ tightly coiled.

Fig. 13. Cell fixed with iodine in KI and photographed with dark-ground illumination to show the three appendages in the fixed condition (for other views see Figs. 17-20). 
J. MAR. BIOL. Ass. U.K., 4I (I)
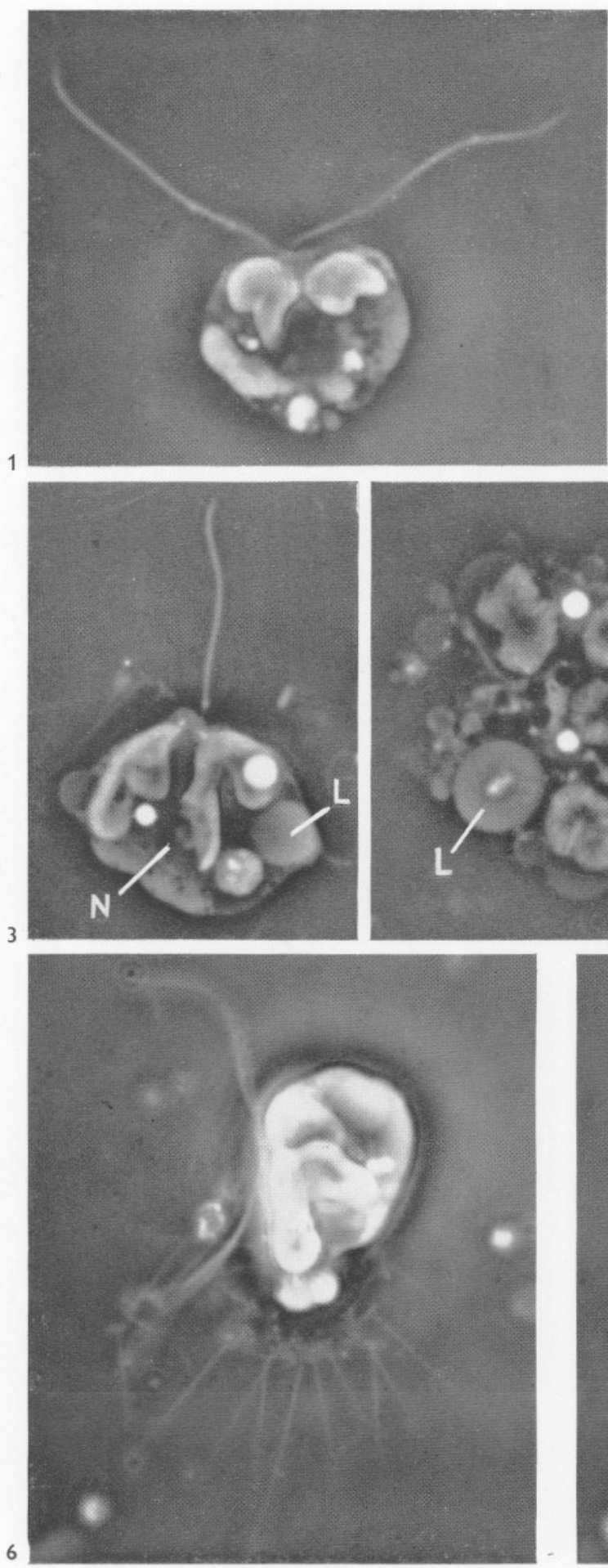

MANTON \& LeEDale. PLATE I

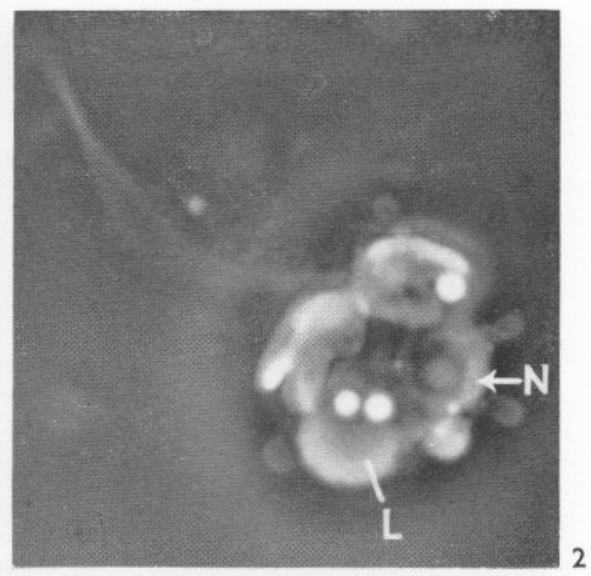

2
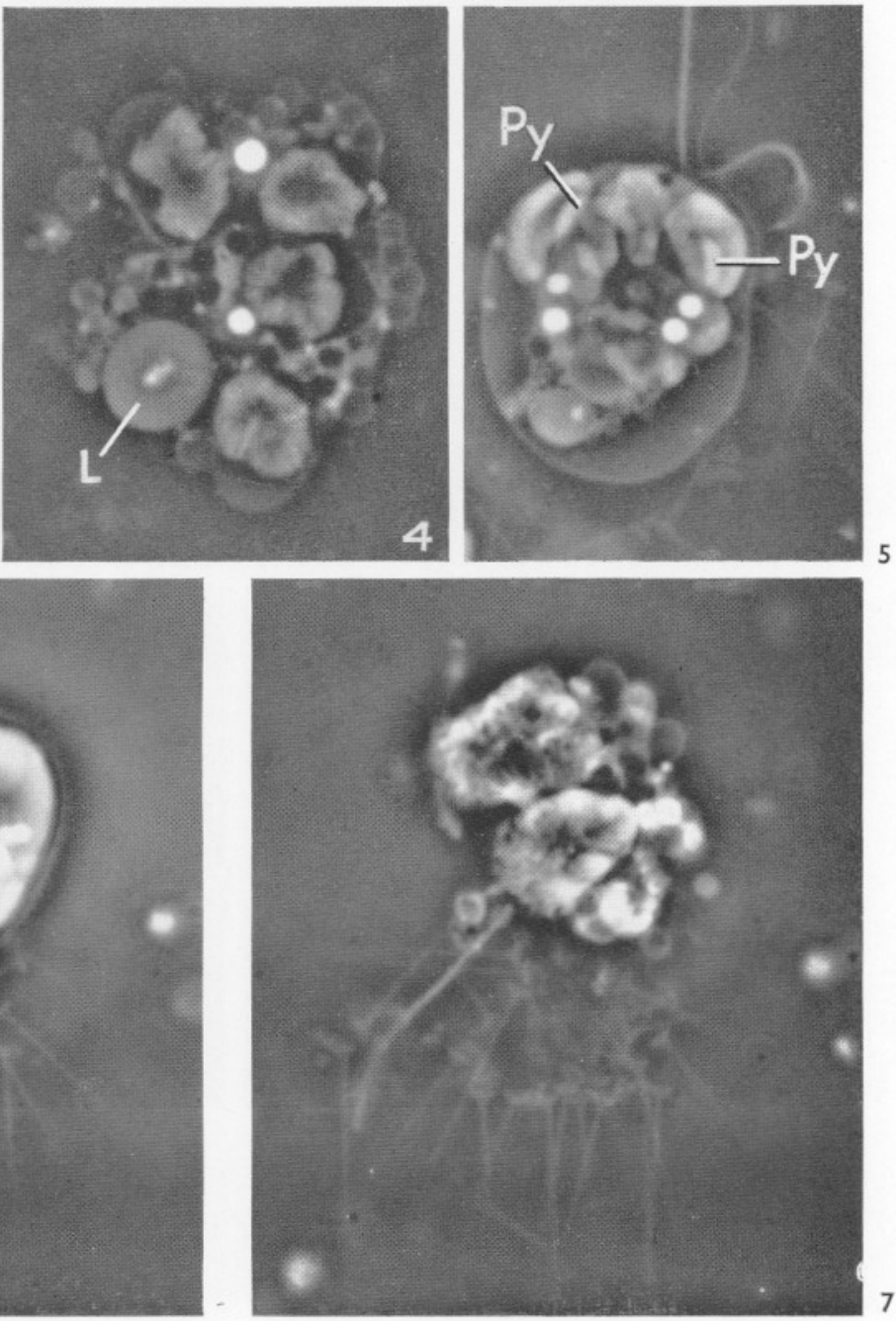

(Facing p. 148) 
J. MAR. BIOL. Ass. U.K., 4I (I)
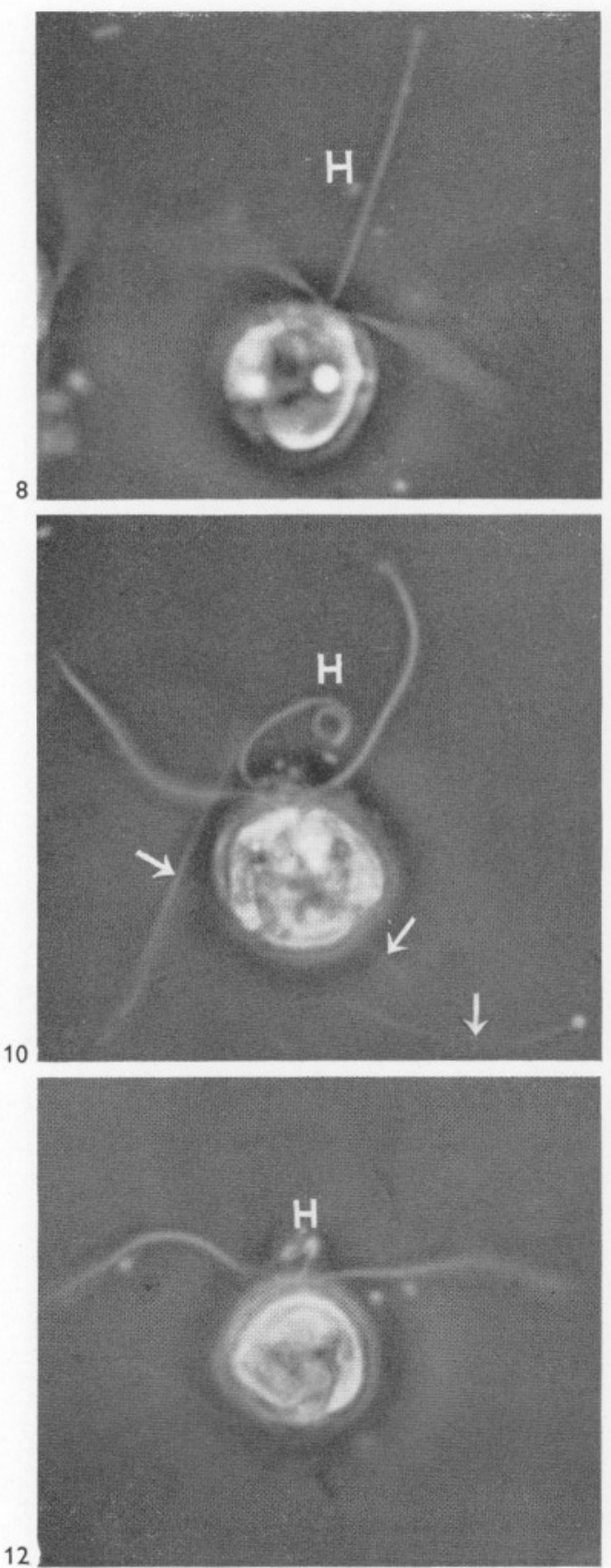

Manton \& Leedale. PLATE II
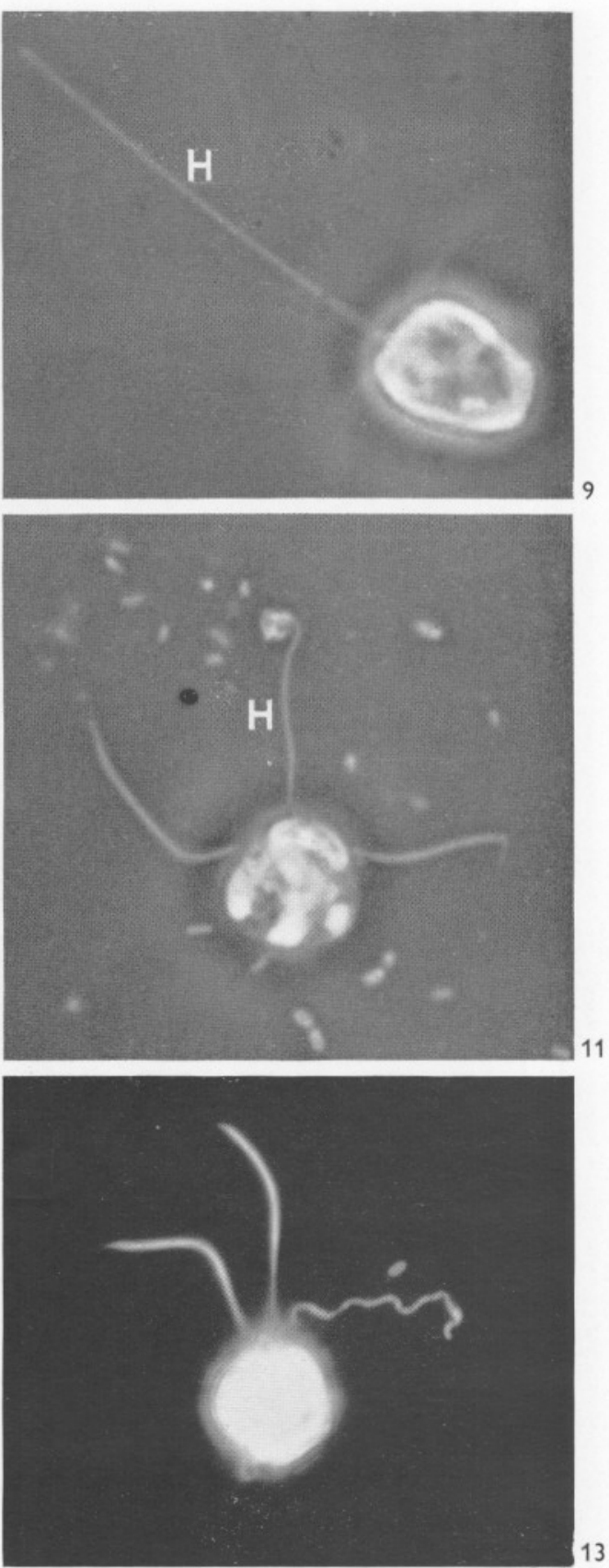


\section{NEW OBSERVATIONS WITH THE ELECTRON MICROSCOPE}

\section{The haptonema}

This is commonly detached from the cells in this species after osmic fixation and therefore the best views of it in position are those taken in life (Plate II) or with the light microscope after iodine fixation (Figs. 17-20). It is, nevertheless, not difficult to pick up intact haptonemata lying loose on the field in shadow-cast preparations and one example is reproduced in Fig. I4. This is doubtless broken off from the cell at or near the point of attachment but the coiled condition involving 8-9 gyres of a solenoid is well preserved.

A similar, detached, haptonema is shown in section in Figs. 15 and 16. Fixation is far from perfect since both blistering and splitting of membranes has occurred locally on a considerable scale. Nevertheless, the best oriented profiles (arrows in Fig. I6) show three concentric membranes surrounding a ring of seven fibres. This is exactly the structure previously described for C. chiton, though not exactly as in C. strobilus.

\section{Pyrenoids}

Figs. 26, 28 and 29 show with sufficient clarity that the pyrenoid here is sunk in the centre of the chromatophore as in C. strobilus. The pyrenoid itself consists of an opaque mass traversed by canaliculi and forming a central swelling in the region which, in a burst cell (Fig. 4), appears featureless. The plastid lamellations proper are probably not individually visible with the light microscope even when striations appear as in Fig. 4, but they can be seen in Figs. 26, 28 and 29 in which they resemble those of other members of the Chrysophyceae.

The unambiguous evidence on pyrenoids obtainable with the electron microscope is in marked contrast to the situation with visual light in which pyrenoids are exceedingly difficult to detect with certainty without the aid of anoptral contrast (see especially Fig. 5). It now seems probable that several references to 'pyrenoid-like bodies' in the literature and in the earlier descriptions of these species (e.g. Text-fig. I and p. 394 of the previous paper) must in fact represent some other, as yet unidentified, cell component.

\section{Golgi structure}

This can be seen in profile in the centre of Fig. 26, occupying a substantial part of the cytoplasm between the two chromatophores. The peculiarity of structure previously encountered for the first time in C. strobilus is again displayed. There is nothing yet to add to the structural interpretation given under that species (Parke et al. 1959), and it is sufficient here to have demonstrated similarity. 


\section{The nucleus}

It is characteristic of this species to have the nucleus in a large proportion of cases apposed to the inner surface of one lobe of a chromatophore, hence its invisibility with the light microscope in a majority of cells. This position is well seen in Fig. 28 and still better in Fig. 29. When most closely apposed to the chromatophore there seems to be a local confluence of membranes resulting in disappearance of the cytoplasmic boundary of the perinuclear space between the two organs. A common cytoplasmic boundary covering both nucleus and chromatophore can then be detected at the two ends of the nucleus (Fig. 29). This feature, which is by no means confined to the present species, is of some electron microscopical interest and will be more fully demonstrated elsewhere.

\section{Other cell inclusions}

The only other cell inclusions to which attention need be directed are (a) certain fibrous connexions from the bases of the appendages, and (b) muciferous bodies. The former are represented in Figs. 27 and 28. A fibrous connexion passing from the lower end of a flagellar base diagonally out to the cell surface is seen in Fig. 27 (arrows), while in Fig. 28 two fibrous connexions, one on each side of the remains of the haptonema base, pass

\section{Explanation of Plates III-VII \\ Chrysochromulina ericina Parke \& Manton}

III

Structure of the haptonema

Fig. I4. A detached coiled haptonema from a shadow-cast whole mount of cells killed directly on a prepared carbon film with osmic vapour. Electron micrograph $\mathrm{H}_{7037}$, magnification $\times 12,000$.

Fig. I5. Section of a detached coiled haptonema. Electron micrograph $\mathrm{H} 6860$, magnification $\times 20,000$.

Fig. I6. More highly magnified part of the preceding showing the three concentric membranes and seven central fibres in the most favourable profiles (arrows). Electron micrograph H 6863, magnification $\times 50,000$.

Figs. 17-20. Intact cells killed with iodine in $\mathrm{KI}$ and photographed with the light microscope under dark ground illumination to show various stages of coiling of the haptonema, magnification $\times$ I000.

\section{IV}

Scale structure

Fig. 2I. Lower end of a spine to show the details of the flared base in a shadow-cast whole mount. Micrograph $\mathrm{H} 7035$, reversed print, $\times 30,000$.

Fig. 22. Median longitudinal section through a spine (selected from a series) with parts of other spines in the background (right) and the edge of a cell (left). Micrograph $\mathrm{H} 7022$ magnification $\times 30,000$.

Fig. 23. Group of plate-scales near the base of a spine to show the pattern of radiating ridges characteristic of one face (contrast with fig. 25). Micrograph $\mathrm{H} 7045$, reversed print, magnification $\times 25,000$. 

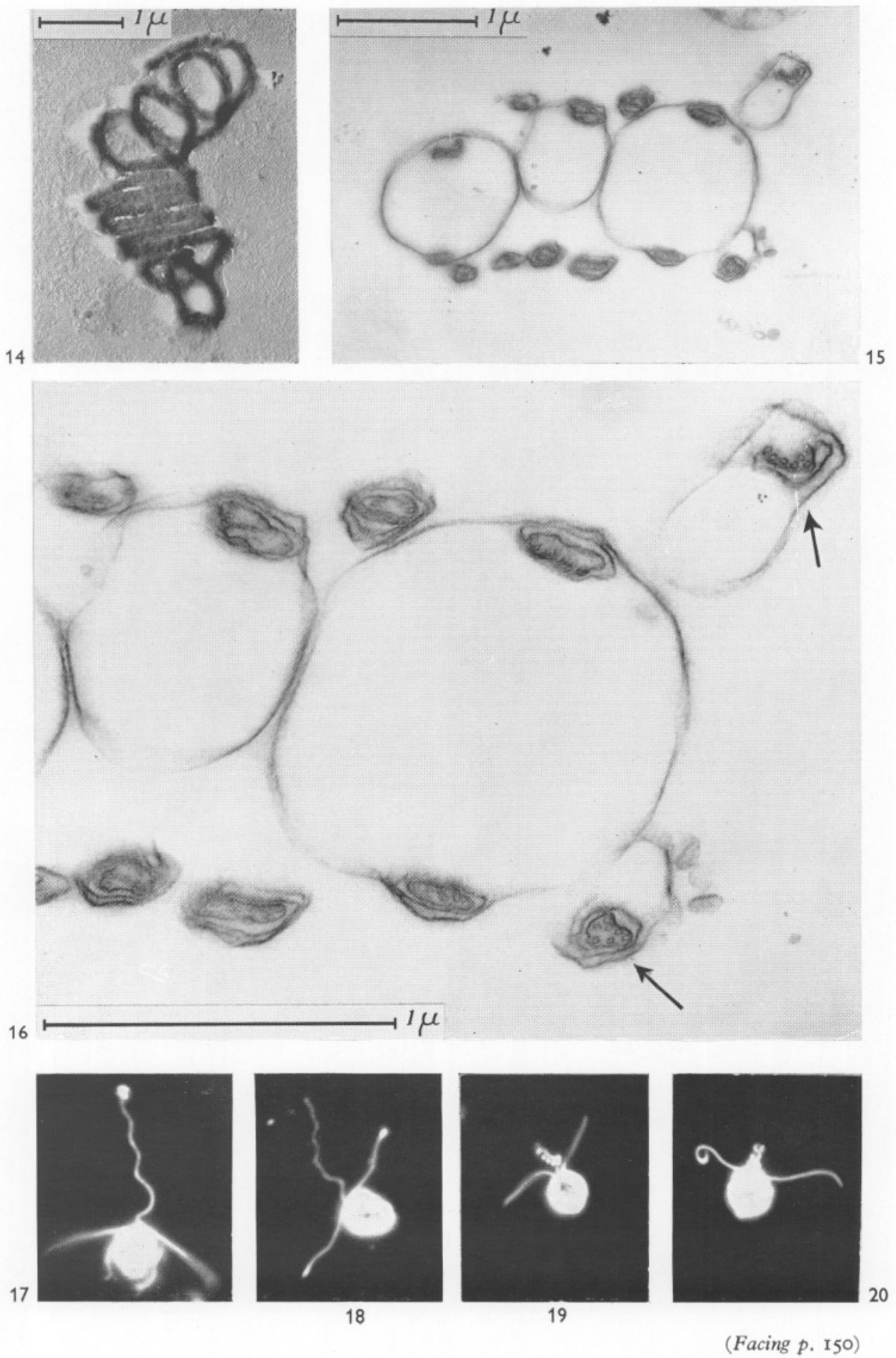


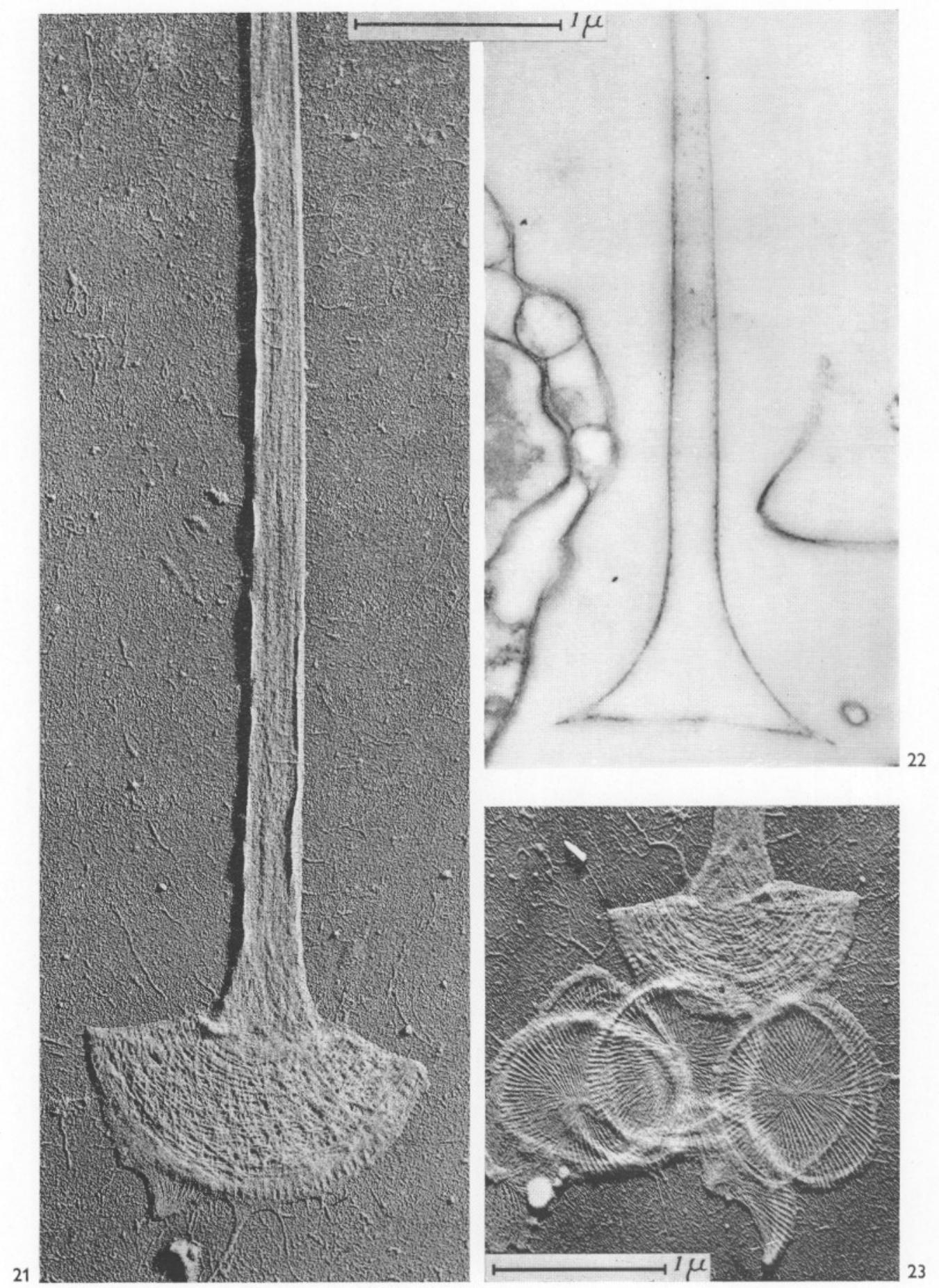



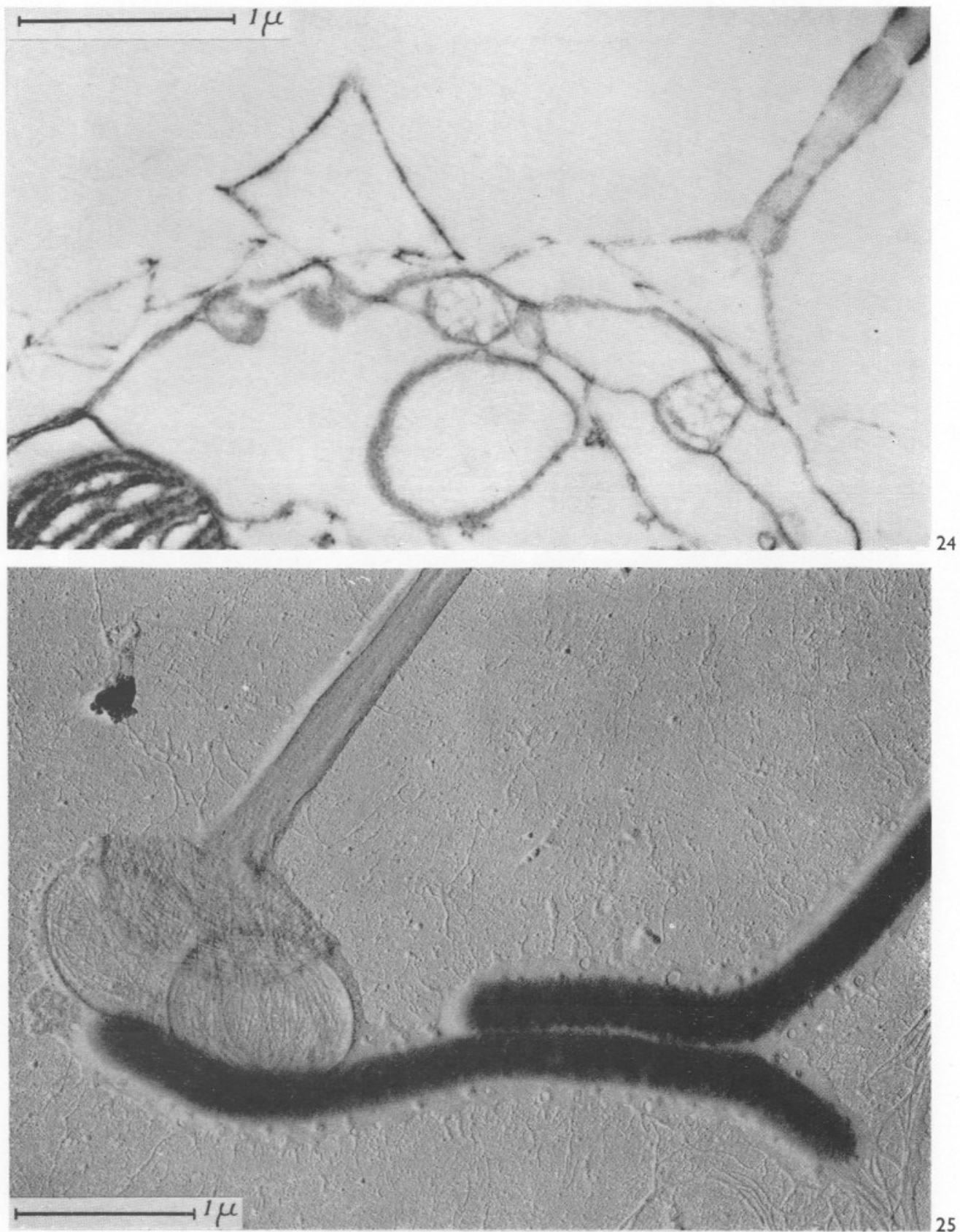

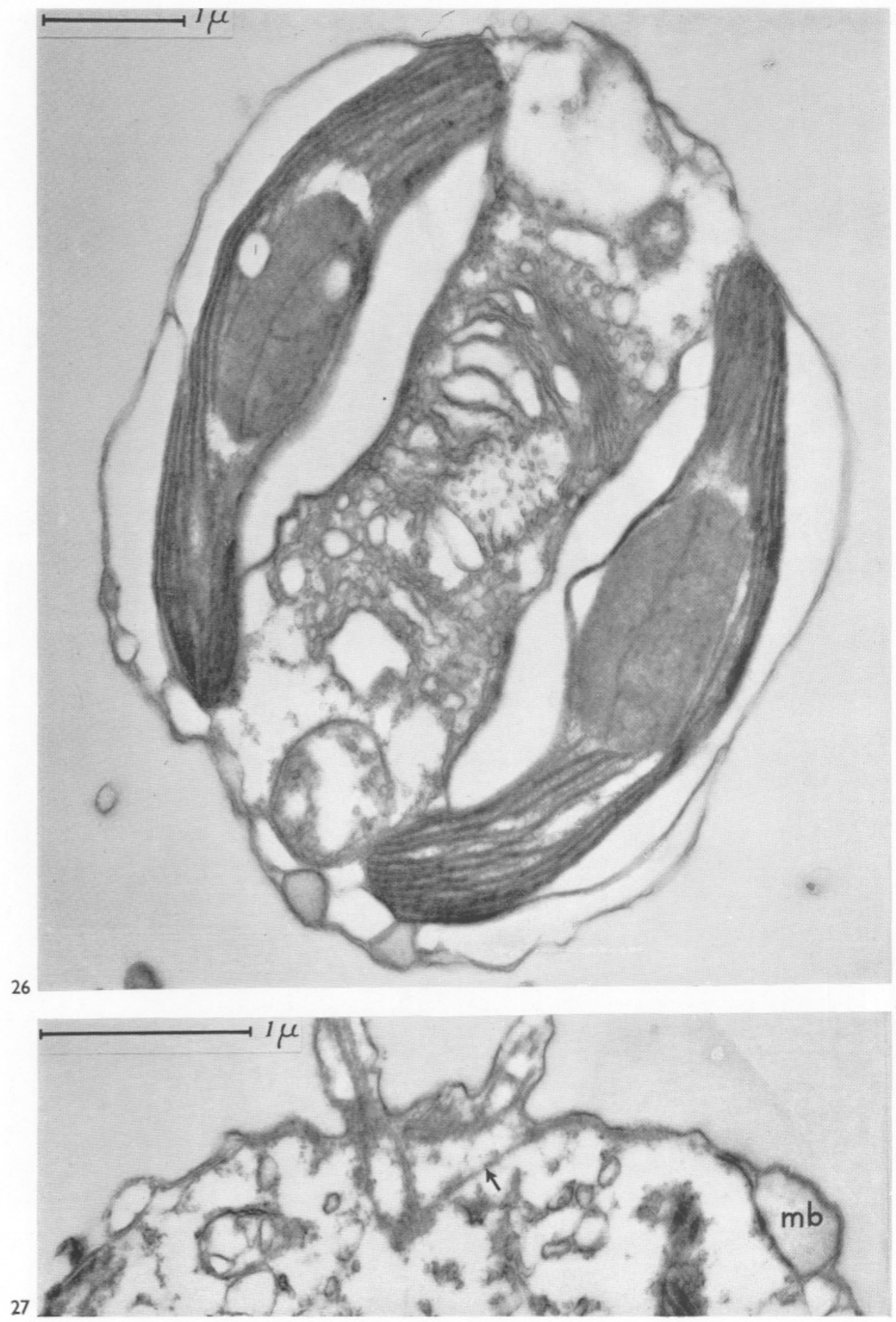

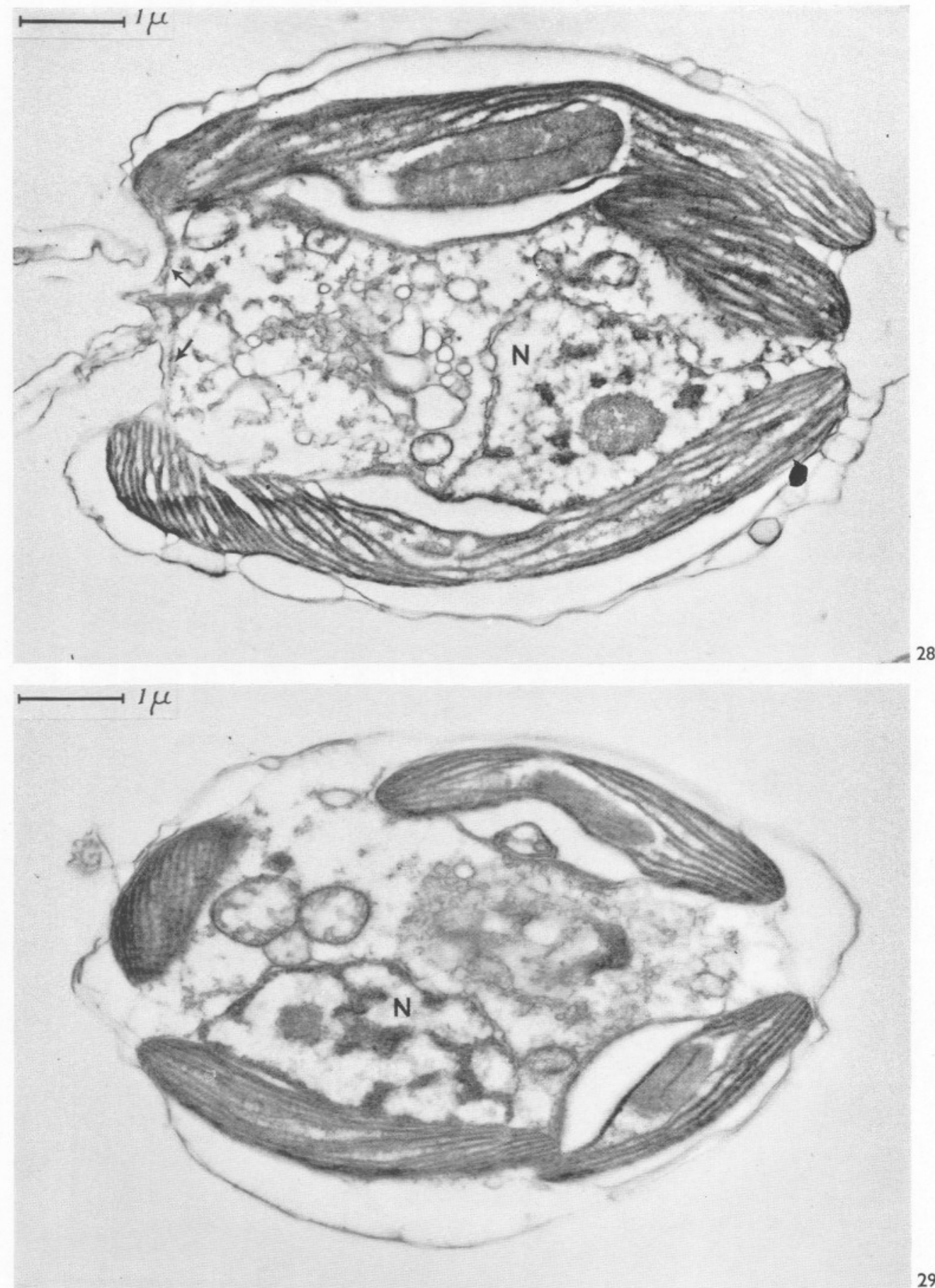


\section{The scales}

These are so important in the present context that two Plates (Pls. IV and V) are devoted to them. It is known from the previous account (Parke et al. 1956) that both spines and plate-scales are present, the latter greatly outnumbering the former though only the spines can be seen individually with the light microscope. The plate-scales have an easily distinguishable difference of pattern on the two faces (Figs. 23, 25), one side being embellished with radiating ridges extending completely to the edge (Fig. 23), the other side having a pattern of concentric or interwoven lines bounded peripherally by an upturned rim (Fig. 25). The flared bases of the spine-scales resemble the latter surface in their marking but it cannot be known from whole mounts whether the spine itself is solid or hollow and whether the flared base is open or closed at the lower end.

These questions are at once answered by a median longitudinal section of a spine (Fig. 22) from which it is quite clear that the spine is hollow and that the lower end of the flared base is closed by a flat plate. With this information available it is possible to extend the description by utilizing a detail often visible in whole mounts but previously uninterpretable. As may be seen on the bottom edge of the base of the spine in Fig. $2 \mathrm{I}$ and again on the left-hand edge of the base of the spine in Fig. 23 there is sometimes a marking resembling a milled rim present on part of the curved lower margin of the flattened spine. It is now obvious that this cannot be a milled rim since it is not uniformly displayed. What we are almost certainly seeing is part of the outer edge of the plate closing the base of the spine which must be carrying a pattern of radiating ridges on its surface of the same type as on the lower face of the plate-scales (Fig. 23).

That this description correctly interprets the orientation of the plate-scales with respect to the subtending cell surface is clearly demonstrated by the occasional fortunate section in which a cell is encountered with its scales in position. Such cells are rare because it is probably only at certain times, in relation to the periodic production of new scales, that these are still firmly enough attached to resist the mechanical disturbance of centrifugation. One example is reproduced in Fig. 24, and it includes both spines and plate-scales. In all the latter the slightly inflexed rim is directed outwards relative to the subtending cell surface. This demonstrates that the outer face is indeed that represented by Fig. 25 and the face against the subtending cell that of Fig. 23. This arrangement, it may be said in passing, is exactly the same as that deduced on other evidence from a different type of spined scale in C. alifera and C. ephippium described at the same time as our present species in 1956 (Parke et al. 1956). 


\section{DISCUSSION}

The new observations on scales are probably the most important single contribution to botanical knowledge which $C$. ericina has provided. A twolayered scale structure had been inferred from morphological evidence for spines of a very different type in C. ephippium and C. alifera (Parke et al. I956), and two separate layers had been directly seen in sections of the very large saucer-shaped scales of $C$. chiton (Parke et al. 1958). This concept could not, however, be further extended until the information regarding the very special type of spine present in $C$. ericina could be completed. The difference between plate-scales and spines in this species represents the most extreme example of scale dimorphism yet encountered in Chrysochromulina and it could not be known a priori whether the spines here might represent an entirely new category of surface appendage. This is, however, undoubtedly not the case. It is now clear that the spines and plate-scales in this species are essentially similar, both being fundamentally two-layered plates which, in the case of the spines, have become modified by a spatial separation of the two layers except at their margin and by an enormous hypertrophy of the outer layer which is not shared by the inner layer. Since changes of relative dimensions in parts of an organ are always some of the easiest modifications to bring about there is no difficulty in regarding the morphological differences between the scales of all four species for which the facts have been directly ascertained (C. ericina, C. alifera, C. ephippium and C. chiton) as relatively minor variants on a common ground plan. Since this ground plan itself is a simple one from which chemical modification by mineralization seems to be entirely lacking it seems likely to be relatively primitive in a group (Chrysophyta) in which extreme complexity of scale structure is often found (the Coccolithophorids and Synura are well known examples). This conclusion will undoubtedly be relevant to an eventual appraisal of the phyletic position of haptonema-bearing organisms within the class.

It had been hoped that the very large size of the spines in C. ericina would make it possible to ascertain some facts about their mode of production by examination of sections. This hope has however not been realized since the absence of mineralization makes recognition of scale fragments encountered in unusual places virtually impossible. It is nevertheless perhaps significant that very large membrane-bounded cavities are sometimes encountered in cells (cf. Fig. 24) and that the arrays of small or middle-sized vesicles present in some cells of $C$. strobilus and $C$. chiton respectively are never found. This suggests that there is a general correspondence between scale size and vesicle size in all three species, which is a fact consistent with, though of course it does not prove, a derivation of scales from internal vesicles and not directly from the cell membrane. Such a production of scales from internal vesicles has recently been directly demonstrated in the unrelated case of Micromonas (Chlorophyceae) (Manton \& Parke, 1960). 
With regard to the other anatomical observations, these can be amplified by the verbal statement that sections of both C. ephippium and C. alifera have been examined in a preliminary way, and both species found to agree exactly with C. ericina in the three characters of haptonema structure, pyrenoid structure and Golgi structure to which attention has been specially directed here. Anatomical information is thus now available for five species attributed to Chrysochromulina namely, C. chiton, C. strobilus, C. ericina, C. ephippium and C. alifera. All of these agree in the essentials of haptonema structure although $C$. strobilus is exceptional in having only six internal fibres, the other four species having seven. C. chiton diverges widely from the others in pyrenoid structure and perhaps also in Golgi structure although reinvestigation of this feature is desirable for this particular species. What, if any, taxonomic significance should be attributed to these differences may be expected to become clearer when corresponding facts are available for the type species of the genus. Since this is expected shortly, further discussion may profitably be deferred.

This work has been carried out in close co-operation with Dr M. Parke, who has supplied the living material and also the photographs taken under dark-ground illumination reproduced as Figs. $17-20$. We are indebted to the Development Commission for financial assistance and to the laboratory staffs of both Plymouth and Leeds for technical assistance. In this category special mention should be made of $\mathrm{Mr} \mathrm{K}$. Oates, senior technician at Leeds, for making the shadow cast preparations of scales represented on Pls. IV and V, Miss Irene Adams of Plymouth for maintaining cultures, and Miss Sheila Wright and $\mathrm{Mr}$ John Greenwell of Leeds for help in the photographic printing.

\section{SUMMARY}

C. ericina Parke \& Manton has been re-investigated to add salient features of micro-anatomy from the electron microscopy of thin sections and also to add photographs of living cells taken with anoptral contrast light microscopy.

The most important new observations concern the scales which are shown to be essentially two-layered plates in which the layers in the very large spined scales have become separated except at their edges, with the outer layer greatly hypertrophied to produce a hollow spine with a flared base closed at the bottom by a flat plate. The patterns of external marking on the two layers are very similar in both plate-scales and spines in this species and the orientation of both with respect to the cell surface has been demonstrated by a section of the scales in situ.

A few new observations are added concerning: (a) fibrous connexions between the bases of the appendages and the cell surface or adjacent chromatophores; (b) muciferous bodies both charged and discharged recorded alive 
and electron microscopically; and $(c)$ an apposition of the nucleus to the surface of a chromatophore.

The remaining anatomical observations are limited to demonstration of the position and general character of the immersed pyrenoid, of the presence of 'peculiar' Golgi structure and of the details of haptonema structure with seven central fibres. Identical characters are reported for C. ephippium and $C$. alifera from sections which are not reproduced, and a comparative summary is given of the anatomical facts now known for five marine species.

\section{REFERENCES}

MANTON, I. \& PARKE, M., I960. Further observations on small green flagellates with special reference to possible relatives of Chromulina pusilla Butcher. F. mar. biol. Ass. U.K., Vol. 39, pp. 275-98.

Parke, M., Manton, I. \& Clarke, B., I955. Studies on marine flagellates. II. Three new species of Chrysochromulina. F. Mar. biol. Ass. U.K., Vol. 34, pp. 579-609. - _ _ 1956. Studies on marine flagellates. III. Three further species of Chrysochromulina. F. mar. biol. Ass. U.K., Vol. 35, pp. 387-4I4.

- 1958. Studies on marine flagellates. IV. Morphology and microanatomy of a new species of Chrysochromulina. F. mar. biol. Ass. U.K., Vol. 37, pp. 209-28.

1959. Studies on marine flagellates. V. Morphology and microanatomy of Chrysochromulina strobilus sp.nov. F. mar. biol. Ass. U.K., Vol. 38, pp. 169-88. 